\title{
Molecular Genetic Characterization of Olpidium virulentus Isolates Associated with Big-Vein Diseased Lettuce Plants
}

L. D. Maccarone, School of Plant Biology, Faculty of Natural and Agricultural Sciences, University of Western Australia, Stirling Highway, Crawley, WA 6009; M. J. Barbetti, School of Plant Biology, Faculty of Natural and Agricultural Sciences, University of Western Australia, Stirling Highway, Crawley, WA 6009, and Agricultural Research Western Australia, Department of Agriculture and Food, Locked Bag No. 4, Bentley Delivery Centre, WA 6983; K. Sivasithamparam, School of Plant Biology, Faculty of Natural and Agricultural Sciences, University of Western Australia, Stirling Highway, Crawley, WA 6009; and R. A. C. Jones, School of Plant Biology, Faculty of Natural and Agricultural Sciences, University of Western Australia, Stirling Highway, Crawley, WA 6009, and Agricultural Research Western Australia, Department of Agriculture and Food, Locked Bag No. 4, Bentley Delivery Centre, WA 6983

\begin{abstract}
Maccarone, L. D., Barbetti, M. J., Sivasithamparam, K., and Jones, R. A. C. 2010. Molecular genetic characterization of Olpidium virulentus isolates associated with big-vein diseased lettuce plants. Plant Dis. 94:563-569.

Lettuce plants showing symptoms of lettuce big-vein disease were collected from fields in the Perth Metropolitan region of southwest Australia. When root extracts from each plant were tested by polymerase chain reaction (PCR) using primers specific to the rDNA internal transcribed spacer (ITS) region of Olpidium brassicae and $O$. virulentus, only $O$. virulentus was detected in each of them. The nucleotide sequences of the complete rDNA ITS regions of isolates from five of the root samples and 10 isolates of $O$. virulentus from Europe and Japan showed 97.9 to $100 \%$ identities. However, with the six O. brassicae isolates, their identities were only 76.9 to $79.4 \%$. On phylogenetic analysis of the complete rDNA-ITS region sequences of the five Australian isolates and 10 others, the Australian isolates fitted within two clades of $O$. virulentus (I and II), and within clade I into two of its four subclades (Ia and Id). Japanese isolates had greatest sequence diversity fitting into both clades and into all of clade I subclades except Ib, while European isolates were restricted to subclades Ib and Id. When the partial rDNA-ITS region sequences of two additional southwest Australian isolates, four from Europe, and four from the Americas were included in the analyses, the Australian isolates were within $O$. virulentus subclades Ia and Id, the European isolates within subclade Ic, and the American isolates within subclades Ia and Ib. These findings suggest that there may have been at least three separate introductions of $O$. virulentus into the isolated Australian continent since plant cultivation was introduced following its colonization by Europeans. They also have implications regarding numbers of different introductions to other isolated regions. Lettuce big-vein associated virus and Mirafiori lettuce big-vein virus were both detected when symptomatic lettuce leaf tissue samples corresponding to the root samples from southwest Australia were tested using virus-specific primers in reverse transcription-PCR, so presence of both viruses was associated with $O$. virulentus occurrence.
\end{abstract}

Lettuce big-vein disease (LBVD) was first found in California (10). It occurs widely in regions of the world with temperate or Mediterranean-type climates and at high altitudes in subtropical regions. LBVD is now known to be associated with a complex of two viruses, Lettuce big-vein associated virus (LBVaV; genus Varicosavirus) and Mirafiori lettuce big-vein virus (MLBVV; genus Ophiovirus) $(17,18,20)$. Its reported natural host range is limited to lettuce (Lactuca sativa), en-

Corresponding author: Roger A. C. Jones

E-mail: roger.jones@agric.wa.gov.au

Accepted for publication 21 December 2009.

doi:10.1094/PDIS-94-5-0563

(C) 2010 The American Phytopathological Society dive (Cichorium endive), spiny sowthistle (Sonchus asper), and common sowthistle (Sonchus oleraceus) $(2,12)$. The vector for both viruses is a root-infecting chytrid belonging to the genus Olpidium (Chytridiomycota). Motile zoospores of this chytrid transmit MLBVV and LBVaV to the roots of healthy plants, and in the absence of susceptible hosts, its resting spores retain the ability to transmit for decades in infested soil $(1,17,19,23)$. In addition to damaging plants' quality through the presence of obvious "big-vein" leaf symptoms (chlorophyll clearing around leaf veins that appear enlarged) from which the disease gets its name, LBVD decreases yield of produce from infected plants substantially $(14,15)$. Symptom expression is most obvious at low temperatures and low light intensities $(2-4,17,27,28)$.
Olpidium spp. are obligate plant pathogens that vector several different soilborne plant viruses. They are found commonly throughout the world infecting the roots of wild and domesticated plants, and until recently only two species were recognized as vectors: $O$. brassicae and $O$. bornovanus $(=O$. radicale $)(2,3,9,19)$. Sahtiyanci (21) separated $O$. brassicae (formerly Pleotrachelus brassicae) into two species: $O$. brassicae being crucifer-infecting and $O$. virulentus non-crucifer-infecting. Morphologically, $O$. brassicae and $O$. virulentus varied slightly. Pleomorphism was present in both species with few variations in $O$. virulentus but more variation in $O$. brassicae. Also, the zoosporangium of $O$. brassicae was larger than that of $O$. virulentus (21). However, this study was overlooked by researchers investigating LBVD, who continued to refer to a non-cruciferinfecting strain of $O$. brassicae as the vector of LBVaV $(2-5,17,19)$. Recently, molecular and host range studies confirmed that $O$. virulentus was sufficiently different to be considered a distinct species that differs from $O$. brassicae in infecting lettuce but not Brassica species, whereas $O$. brassicae infects Brassica species but not lettuce $(7,13,23)$. Nucleotide sequence data for the rDNA internal transcribed spacer (ITS) region of its Olpidium sp. vector confirmed that it was $O$. virulentus that transmitted MLBVV and the Tobacco stunt virus (TStV) strain of $\mathrm{LBVaV}$ to lettuce roots (23).

In Australia, LBVD is a widespread problem in commercial lettuce producing areas. In southwest Australia, the lettuce production system on the Swan Coastal Plain is intensive and often uses irrigated land that is contaminated with LBVD, sometimes without crop rotation. Also, winter plantings often have $>90 \%$ of plants with symptoms of the disease $(12,14,15)$. However, no nucleotide sequences of $\mathrm{Ol}$ pidium spp. are available from the Australian continent. This paper reports studies that determined the nucleotide sequences of the rDNA ITS region of southwest Australian Olpidium sp. isolates obtained from the roots of lettuce plants with LBVD, and 
compared their sequence identities and phylogenies with those of the rDNA ITS region of Olpidium spp. isolates from elsewhere.

\section{MATERIALS AND METHODS}

Collection of field samples. Whole lettuce plants showing LBVD symptoms were sampled from two crops growing in the northern Perth Metropolitan region of southwest Australia. They came from two different commercial lettuce growing farms, four samples from one farm (labeled Nan 6, Nan 7, Nan 8, and T1 23) and three from the other (labeled Col 1, Col 2, and $\mathrm{Col} 3$ ). On the same day, roots from each sample were washed and ground in liquid nitrogen before DNA was extracted and stored at $-20^{\circ} \mathrm{C}$.

DNA extraction, polymerase chain reaction (PCR), and agarose gel electrophoresis. Total DNA was extracted from the lettuce root tissue from samples Nan 6 to 8 , T1 23, and Col 1 to 3 using a Qiagen DNeasy Plant Mini Kit (Qiagen Inc., Valencia, CA) according to manufacturer's instructions. No cultures of $O$. brassicae or $O$. virulentus were available to provide positive control extracts. Primers used to amplify target Olpidium spp. came from White et al. (30) (ITS1 and ITS4) or were designed from within the rDNA-ITS region by aligning already known sequences using BioEdit (6) (Ob1, Ob2, Ov1, and Ov2). For amplification of $O$. brassicae, the primer pairs used were Ob1 Fwd (5' TCA TTA ATA AAT GCT TCA TTG CAT $\left.3^{\prime}\right)$ with ITS4 Rev (5' TCC TCC GCT TAT TGA TAT GC $\left.3^{\prime}\right)$, and ITS 1 Fwd (5' TCC GTA GGT GAA CCT GCG G 3') (30) with Ob2 Rev (5' TCC AGC AAC AAG TCT TCC CAA 3'). For $O$. virulentus amplification, the primer pairs used were Ov1 Fwd (5' CAA GAC CTG CCC CCA AAA GGG $\left.3^{\prime}\right)$ with ITS4, and ITS1 with Ov2 Rev (5' CCA AGT TCG CAA ACG TGG CG 3'). All primer pair combinations were used on tissue extracts from each sample. PCR reactions were done using Taq DNA polymerase and $5 \times$ polymerization buffer (Fisher Biotec, Perth, Western Australia).

PCR amplification conditions consisted of 1 min denaturation at $94^{\circ} \mathrm{C}$ followed by 35 cycles of $94^{\circ} \mathrm{C}$ for $30 \mathrm{~s}, 60^{\circ} \mathrm{C}$ for $30 \mathrm{~s}$, and $72^{\circ} \mathrm{C}$ for $1 \mathrm{~min}$ followed by a final extension at $72^{\circ} \mathrm{C}$ for $10 \mathrm{~min}$ before being held at $14^{\circ} \mathrm{C}$. PCR amplicons were visualized by electrophoresis on $1 \%$ agarose gels. Tris-boric acid-EDTA (TBE) electrophoresis buffer was used (22).

Virus RNA extraction and multiplex reverse transcription (RT)-PCR. Symptomatic leaf tissue samples corresponding to six of the seven root samples were used for RNA extraction (isolate T1 23 was not available). Total RNA was extracted from each sample using an UltraClean Plant RNA Isolation Kit (MoBio Laboratories, Inc.) according to manufacturer's instructions. RNA extracts were stored at $-80^{\circ} \mathrm{C}$.
Three primer pairs developed by Navarro et al. (18) were used for multiplex RTPCR: VP248 Fwd (5' CGC CAG GAT CTT TGA TCC ATC TG 3') with VP249 Rev (5' TTG CGA CAT GTT CCT CCT CAT CG 3') to amplify LBVaV, VP286 Fwd (5' TAT CAG CTC ACA TAC TCC CTA TCG $3^{\prime}$ ) with VP287 Rev (5' CAA CTA GCT CAG AAT ACA TGC AG $3^{\prime}$ ) to amplify MLBVV, and control primers VP383 Fwd (5' AGC GTG CTA ATC CCT ATG TTC AT $\left.3^{\prime}\right)$ with VP389 Rev (5' AAT GAA AAT CTT AAA AGC CGT AG $3^{\prime}$ ) to amplify the mitochondrial NADH dehydrogenase subunit 4 (nad4) of lettuce. RTPCR was done using a OneStep RT-PCR kit (Qiagen, Australia) according to manufacturer's instructions.

PCR amplification conditions consisted of $50^{\circ} \mathrm{C}$ for $30 \mathrm{~min}, 95^{\circ} \mathrm{C}$ for $15 \mathrm{~min}$ followed by 30 cycles of $94^{\circ} \mathrm{C}$ for $1 \mathrm{~min}$, $55^{\circ} \mathrm{C}$ for $1 \mathrm{~min}$, and $72^{\circ} \mathrm{C}$ for $1 \mathrm{~min}$ followed by a final extension at $72^{\circ} \mathrm{C}$ for 10 min before being held at $14^{\circ} \mathrm{C}$.

Cloning and sequencing of PCR amplicons. PCR amplicons of Olpidium were purified by ethanol precipitation and then quantified using a Nanodrop UV-Vis spectrophotometer following the manufacturer's protocol. Next, standard ligation and transformation reactions were done into JM109 competent cells using a pGEM®-T Easy Vector (Promega Corp, Madison, WI) as recommended in the manufacturer's protocol.

Table 1. Details of isolates of three vector Olpidium spp. used to determine relationships using the nucleotide sequences of their rDNA internal transcribed spacer regions

\begin{tabular}{|c|c|c|c|c|c|}
\hline Species & Accession no. & Isolate & Geographic origin & Isolated from root of & Reference \\
\hline O. bornovanus & AB205214 & NA & Nagasaki, Japan & Melon & 23 \\
\hline O. bornovanus & AB205215 & $\mathrm{CH}$ & Chiba, Japan & Melon & 23 \\
\hline O. brassicae & AB205209 & CBG-3 & Nagano, Japan & Cabbage & 23 \\
\hline O. brassicae & AB205210 & NKa-3 & Nagano, Japan & Cabbage & 23 \\
\hline O. brassicae & AB205211 & YR-2 & Shimane, Japan & Cabbage & 23 \\
\hline O. brassicae & AB205212 & ZE-1 & Zentsuji, Japan & Cabbage & 23 \\
\hline O. brassicae & AB205213 & EH-2 & Iyo, Japan & Cabbage & 23 \\
\hline O. brassicae & AY373015 & GBR7 & Warwickshire, UK & Cauliflower & 7 \\
\hline O. virulentus & AB205203 & WT-1 & Wakayama, Japan & Lettuce & 23 \\
\hline O. virulentus & AB205204 & HY-1 & Hyougo, Japan & Lettuce & 23 \\
\hline O. virulentus & AB205205 & KZ-1 & Kagawa, Japan & Lettuce & 23 \\
\hline O. virulentus & AB205206 & TAK-1 & Takamatsu, Japan & Tobacco & 23 \\
\hline O. virulentus & AB205207 & $\mathrm{CH}-1$ & Chunan, Japan & Tobacco & 23 \\
\hline O. virulentus & AB205208 & WOms-3 & Toyama, Japan & Welsh onion & 23 \\
\hline O. virulentus & AY373011 & GBR1 & Warwickshire, UK & Lettuce & 7 \\
\hline O. virulentus & AY373012 & ITA1 & Mirafiori, Italy & Lettuce & 7 \\
\hline O. virulentus & AY373013 & NLD4 & De Lier, the Netherlands & Lettuce & 7 \\
\hline O. virulentus & AY373014 & GBR10 & Humberside, UK & Cucumber & 7 \\
\hline O. virulentus & AY997067 & 633 & Duke University Herbarium, USA & Unknown & 11 \\
\hline O. virulentus & EU981898 & GT-8 & Zacapa, Guatemala & Cantaloupe & 9 \\
\hline O. virulentus & EU981899 & MX-06 & Sinaloa, Mexico & Cantaloupe & 9 \\
\hline O. virulentus & EU981900 & MX-05 & Colima, Mexico & Cantaloupe & 9 \\
\hline O. virulentus & EU981901 & SP-08 & Castellon, Spain & Lettuce & 9 \\
\hline O. virulentus & EU981902 & SP-09 & Murcia, Spain & Tomato & 9 \\
\hline O. virulentus & EU981903 & SP-07 & Alicante, Spain & Watermelon & 9 \\
\hline O. virulentus & EU981905 & SP-06 & Seville, Spain & Cantaloupe & 9 \\
\hline O. virulentus & GQ304519 & Nan6 & Perth, Western Australia & Lettuce & This study \\
\hline O. virulentus & GQ304520 & Nan7 & Perth, Western Australia & Lettuce & This study \\
\hline O. virulentus & GQ304521 & Nan8 & Perth, Western Australia & Lettuce & This study \\
\hline O. virulentus & GQ304522 & $\mathrm{T}_{1} 23$ & Perth, Western Australia & Lettuce & This study \\
\hline O. virulentus & GQ304523 & Col1 & Perth, Western Australia & Lettuce & This study \\
\hline O. virulentus & GQ328050 & $\mathrm{Col} 2$ & Perth, Western Australia & Lettuce & This study \\
\hline O. virulentus & GQ328051 & $\mathrm{Col} 3$ & Perth, Western Australia & Lettuce & This study \\
\hline
\end{tabular}


Screening for recombinant plasmids was done using M13 primers Fwd (5' CGT CAG GCT TTT CCC AGT CAC GAC 3') and Rev (5' TCA CAC AGG AAA CAG CTA TGA C $3^{\prime}$ ). Amplification conditions consisted of $1 \mathrm{~min}$ denaturation at $94^{\circ} \mathrm{C}$ followed by 25 cycles of $94^{\circ} \mathrm{C}$ for $30 \mathrm{~s}$, $55^{\circ} \mathrm{C}$ for $30 \mathrm{~s}$, and $72^{\circ} \mathrm{C}$ for $30 \mathrm{~s}$ before being held at $14^{\circ} \mathrm{C}$. Amplicons were then visualized on $1 \%$ agarose gels as described above. Recombinant plasmids were inoculated into $5 \mathrm{ml}$ of Luria Bertani (LB) broth with ampicillin (100 mg/liter) and incubated on a shaker at $37^{\circ} \mathrm{C}$ overnight. Plasmids were then purified from the culture using an Aurum Bio-Rad Plasmid Extraction Kit following the manufacturer's instructions. Presence and size of inserts was confirmed with a restriction digest of the purified plasmid DNA by EcoR1 $(10 \mu \mathrm{l}$ of purified plasmid DNA, $2 \mu \mathrm{l}$ of $10 \times E c o$ R 1 buffer, $1 \mu \mathrm{l}$ of EcoR1, and $7 \mu \mathrm{l}$ of water), incubating on a $37^{\circ} \mathrm{C}$ heat block for $1 \mathrm{~h}$, and visualizing on $1 \%$ agarose gel.

Dideoxy-termination sequencing was done at the Western Australian State Agricultural Biotechnology Centre (SABC), Murdoch University, Perth, or Royal Perth Hospital, Perth. In both instances, Big Dye Version 3.1 chemistry was used. The complete rDNA-ITS sequences of isolates Nan 6 to 8, T1 23, and Col 1 (each $632 \mathrm{bp}$ ) and partial sequences of isolates Col 2 (577 bp) and $\mathrm{Col} 3$ (503 bp) were submitted to GenBank (Table 1).

Analysis of sequence data. Nucleotide sequence data for the 21 complete rDNAITS regions (632 bp) of Olpidium spp. and the 10 partial rDNA-ITS regions (503 to 577 bp) were assembled and analyzed using Molecular Evolutionary Genetics Analysis (MEGA) program Version 4.1 (24). Sequence data for the rDNA ITS region of six full-length sequences of $O$. brassicae, 10 full-length sequences of $O$. virulentus from Europe and Japan, and eight partial sequences from the Americas and Europe were retrieved from GenBank (Table 1). Isolates SP-010 from Spain (EU981907) and PT-01 from Portugal (EU981906) were excluded from this analysis, as they were only $176 \mathrm{bp}$ in length (8).

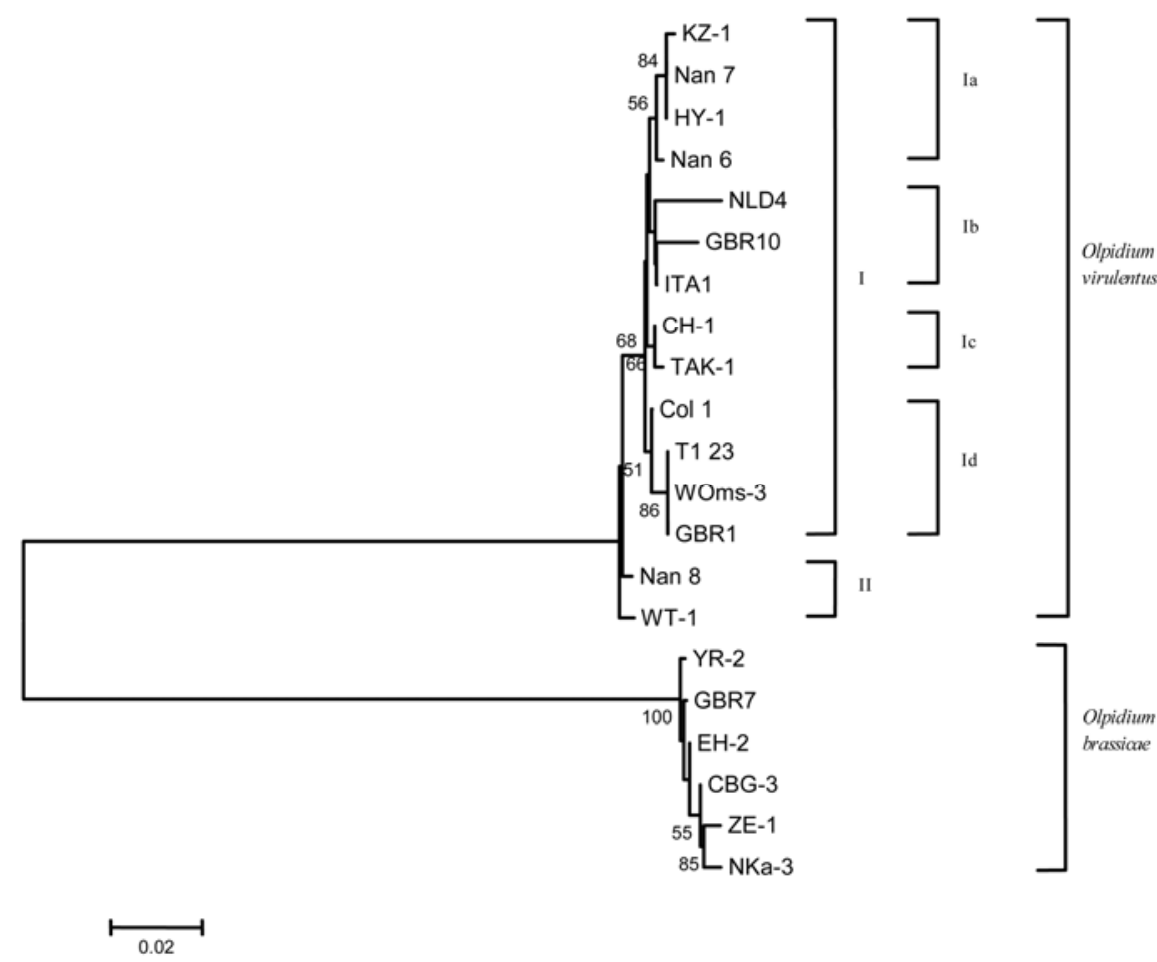

Fig. 1. Unrooted neighbor-joining relationship dendrogram for the complete 632-bp rDNA internal transcribed spacer nucleotide sequences of five Olpidium isolates sequenced in this study and 16 others from Europe and Japan available on GenBank. The phylogenetic tree was generated using MEGA 4.1 using the default parameters. Tree branches were bootstrapped with 1,000 replications. Numbers at nodes indicate bootstrap scores $>50 \%$. Scale bar represents a genetic distance of 0.02 for horizontal branch lengths. Table 1 shows isolate designations.

Table 2. Estimates of evolutionary percent identity between isolates of Olpidium virulentus and $O$. brassicae based on nucleotide sequence alignment of the complete rDNA internal transcribed spacer region

\begin{tabular}{|c|c|c|c|c|c|c|c|c|c|c|c|c|c|c|c|c|c|c|c|c|c|}
\hline & $\mathrm{KZ}-1$ & Nan7 & Нy-1 & Nan6 & NDL4 & GBR10 & ITA1 & Col1 & T123 & WOms 3 & GBR1 & $\mathrm{CH}-1$ & TAK-1 & Nan8 & WT-1 & YR-2 & $\mathrm{EH}-2$ & CBG -3 & GBR7 & $\mathrm{ZE}-1$ & NKa3 \\
\hline $\mathrm{KZ}-1$ & & 99.8 & 99.8 & 99.4 & 98.3 & 98.3 & 99.3 & 99.1 & 98.9 & 98.9 & 98.9 & 99.3 & 99.1 & 98.7 & 98.5 & 78.2 & 78.2 & 77.9 & 77.7 & 77.4 & 77.4 \\
\hline Nan7 & & & 100 & 99.6 & 98.5 & 98.5 & 99.4 & 99.3 & 99.1 & 99.1 & 99.1 & 99.4 & 99.3 & 98.9 & 98.7 & 78.4 & 78.4 & 78.2 & 77.9 & 77.7 & 77.6 \\
\hline $\mathrm{HY}-1$ & & & & 99.6 & 98.5 & 98.5 & 99.4 & 99.3 & 99.1 & 99.1 & 99.1 & 99.4 & 99.3 & 98.9 & 98.7 & 78.4 & 78.4 & 78.2 & 77.9 & 77.7 & 77.6 \\
\hline Nan6 & & & & & 98.9 & 98.5 & 99.4 & 99.3 & 99.1 & 99.1 & 99.1 & 99.4 & 99.3 & 98.9 & 98.7 & 78.7 & 78.7 & 78.5 & 78.2 & 77.9 & 77.9 \\
\hline NLD4 & & & & & & 98.1 & 99.1 & 98.5 & 98.3 & 98.3 & 98.3 & 98.7 & 98.5 & 98.1 & 97.9 & 77.7 & 77.7 & 77.4 & 77.2 & 76.9 & 76.9 \\
\hline GBR10 & & & & & & & 99.1 & 98.5 & 98.3 & 98.3 & 98.3 & 98.7 & 98.5 & 98.1 & 97.9 & 78.4 & 78.4 & 78.1 & 77.9 & 77.6 & 77.6 \\
\hline ITA1 & & & & & & & & 99.4 & 99.3 & 99.3 & 99.3 & 99.6 & 99.4 & 99.1 & 98.9 & 78.7 & 78.7 & 78.4 & 78.2 & 77.9 & 77.9 \\
\hline Col1 & & & & & & & & & 99.4 & 99.4 & 99.4 & 99.4 & 99.3 & 98.9 & 98.7 & 78.4 & 78.4 & 78.2 & 77.9 & 77.7 & 77.7 \\
\hline T123 & & & & & & & & & & 100 & 100 & 99.3 & 99.1 & 98.7 & 98.5 & 78.9 & 78.9 & 78.7 & 78.4 & 78.2 & 78.1 \\
\hline WOms 3 & & & & & & & & & & & 100 & 99.3 & 99.1 & 98.7 & 98.5 & 78.9 & 78.9 & 78.7 & 78.4 & 78.2 & 78.1 \\
\hline GBR1 & & & & & & & & & & & & 99.3 & 99.1 & 98.7 & 98.5 & 78.9 & 78.9 & 78.7 & 78.4 & 78.2 & 78.1 \\
\hline $\mathrm{CH}-1$ & & & & & & & & & & & & & 99.8 & 99.1 & 98.9 & 78.9 & 78.9 & 78.7 & 78.4 & 78.2 & 78.1 \\
\hline TAK-1 & & & & & & & & & & & & & & 98.9 & 98.7 & 78.9 & 78.9 & 78.7 & 78.4 & 78.2 & 78.1 \\
\hline Nan8 & & & & & & & & & & & & & & & 99.4 & 79.4 & 79.4 & 79.1 & 78.9 & 78.6 & 78.6 \\
\hline WT - 1 & & & & & & & & & & & & & & & & 79.4 & 79.4 & 79.2 & 78.9 & 78.7 & 78.6 \\
\hline YR-2 & & & & & & & & & & & & & & & & & 99.6 & 99.8 & 99.6 & 99.4 & 99.4 \\
\hline EH - 2 & & & & & & & & & & & & & & & & & & 99.8 & 99.6 & 99.4 & 99.4 \\
\hline CBG- 3 & & & & & & & & & & & & & & & & & & & 99.8 & 99.6 & 99.6 \\
\hline GBR7 & & & & & & & & & & & & & & & & & & & & 99.4 & 99.4 \\
\hline $\mathrm{ZE}-1$ & & & & & & & & & & & & & & & & & & & & & 99.3 \\
\hline NKa-3 & & & & & & & & & & & & & & & & & & & & & \\
\hline
\end{tabular}


with 1,000 resamplings. This process was then repeated to also include the two partial sequences from southwest Australia and the other eight partial sequences. Evolutionary history was inferred using the neighbor-joining method initially for the 21 full-length sequences only and then for all 31 sequences. Evolutionary distances were computed using the Maximum Composite Likelihood method. All positions containing gaps and missing data were eliminated from the dataset (complete deletion option). Two sequences of $O$. bornovanus were then added to the alignment and a radiation diagram constructed to show the relative genetic distance between the different species of Olpidium reported to be virus vectors.

\section{RESULTS}

PCR DNA extracts from roots. PCR amplification of the rDNA-ITS nucleotide sequence from all seven root samples using primers designed specifically for $O$. virulentus always revealed presence of this Olpidium species. However, primers designed specifically for $O$. brassicae produced only one very faint amplicon from one sample. Subsequent sequencing of this band failed, suggesting that $O$. brassicae was absent, which is consistent with recent findings that this species does not infect lettuce $(7,13,23)$.

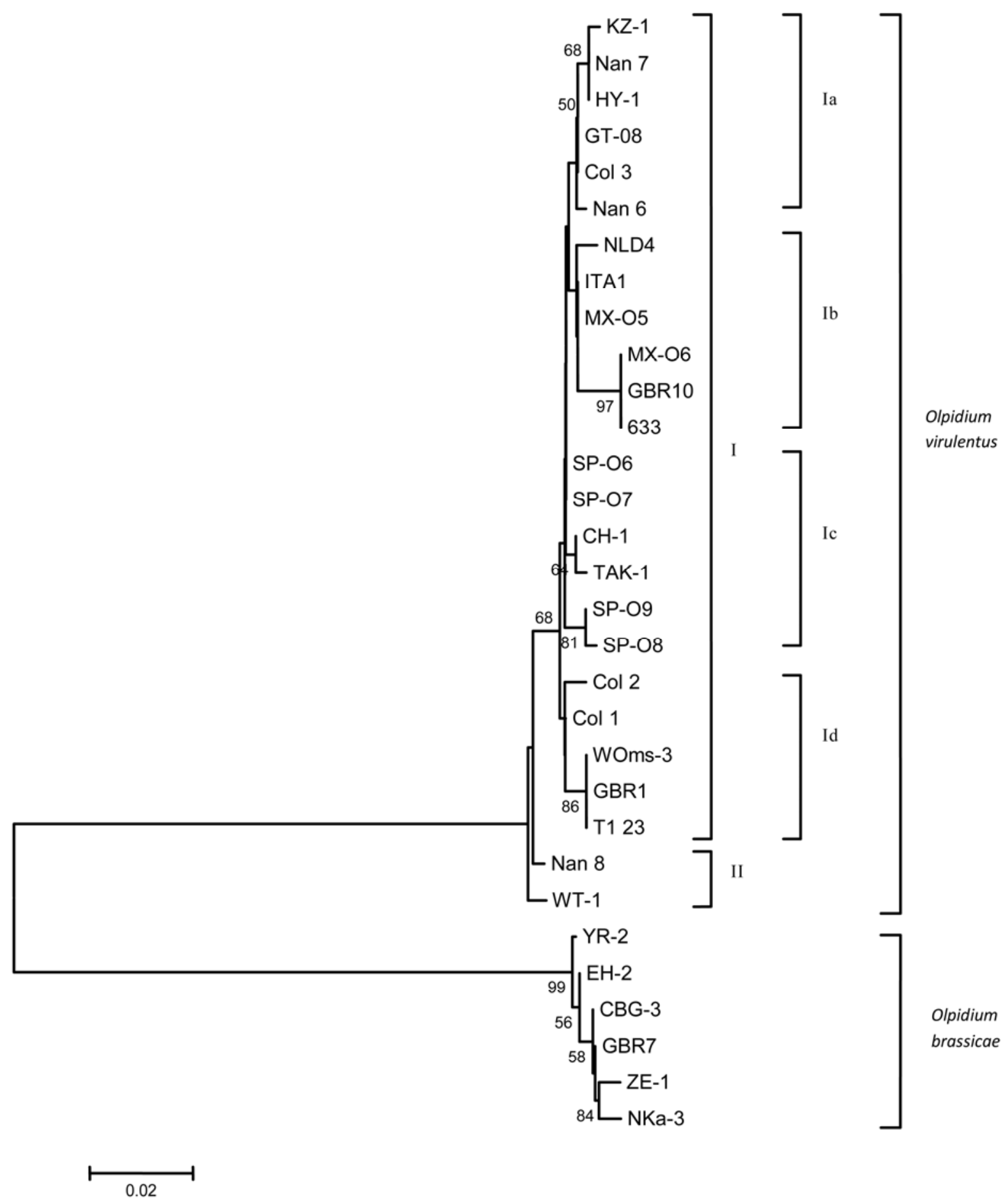

Fig. 2. Unrooted neighbor-joining relationship dendrogram for rDNA internal transcribed spacer nucleotide sequences of the five complete and two partial Olpidium isolates sequenced in this study and 16 complete and eight partial ones from Europe, Japan, and the Americas available on GenBank. The phylogenetic tree was generated using MEGA 4.1 using the default parameters. Tree branches were bootstrapped with 1,000 replications. Numbers at nodes indicate bootstrap scores $>50 \%$. Scale bar represents a genetic distance of 0.02 for horizontal branch lengths. Table 1 shows isolate designations. 
Nucleotide sequence identities. Of the 21 Olpidium complete rDNA-ITS region nucleotide sequences analyzed, those of the five southwest Australian isolates showed greatest nucleotide identity with those of $O$. virulentus (four isolates from Europe and six from Japan) (Table 2). Overall, there was 97.9 to $100 \%$ identity between the 15 isolates of O. virulentus, and 99.3 to $100 \%$ identity between the six isolates of $O$. brassicae. However, the identity between $O$. virulentus and $O$. brassicae sequences was only 76.9 to $79.4 \%$.

Phylogenetic analysis. The five $\mathrm{Ol}$ pidium sp. isolates with complete rDNAITS nucleotide sequences from southwest Australia all grouped with $O$. virulentus (Fig. 1). They fitted into two O. virulentus clades, I and II. Although the rDNA-ITS region of Olpidium is highly conserved, it was also possible to distinguish subclades within clade I despite the small overall sequence divergence. Four isolates fitted into clade I within two of its four subclades (Ia-d). Nan 6 and Nan 7 grouped together with Japanese isolates KZ-1 and HY-1 within subclade Ia, while T1 23 and Col 1 grouped with Japanese isolate WOms-3 and UK isolate GBR1 within subclade Id. Subclade Ib contained one isolate each from the Netherlands (NLD4), Great Britain (GBR10), and Italy (ITA1). The third subclade, Ic, contained two isolates from Japan (CH-1 and TAK-1). Australian isolate Nan 8 grouped with Japanese isolate WT-1, and these isolates were more distant genetically from the others forming a distinct clade on their own (clade II).

When the 10 partial sequences are added to the phylogeny (Fig. 2), subclade Ia then also included an Australian isolate ( $\mathrm{Col} 3$ ) and one from Guatemala (GT-08), subclade Ib contained two isolates from Mexico (MX-05 and MX-06) and one from the United States (633), four isolates from Spain (SP-06 to SP-09) were in subclade Ic, and the remaining Australian isolate (Col 2) fitted into subclade Id. None of the partial sequences fell within clade II.

When the relative genetic distances between the three viral vector species of Olpidium were compared, O. virulentus and $O$. brassicae were much closer to one another than either was to $O$. bornovanus (Fig. 3).

RT-PCR RNA extracts from leaves. When leaf tissue from samples Nan 6 to 8 and Col 1 were tested by RT-PCR using primers specific for LBVaV or MLBVV, a 496-bp fragment was amplified indicating presence of MLBVV, a 292-bp fragment indicating presence of $\mathrm{LBVaV}$, and a 360bp control fragment indicating presence of the nad4 gene of lettuce (Fig. 4). This shows that both viruses were present in each of the samples. Leaf tissue from samples $\mathrm{Col} 2$ and $\mathrm{Col} 3$ were also tested using the same method. Col 2 contained both viruses, while MLBVV was the only virus present in Col 3. As O. virulentus, but not
$O$. brassicae, was associated with the two viruses in the same lettuce plants, this indicates that it may have been responsible for the transmission of LBVaV and MLBVV on the two farms originally sampled.

\section{DISCUSSION}

This study revealed that $O$. virulentus, but not $O$. brassicae, was associated with samples of lettuce plants with LBVD collected from two farms in southwest Australia, and that the same samples were infected either with LBVaV and MLBVV, or MLBVV alone. This association of $O$. virulentus with the two viruses is consistent with previous research which suggested that $O$. virulentus, rather than $O$. brassicae, was the chytrid vector of

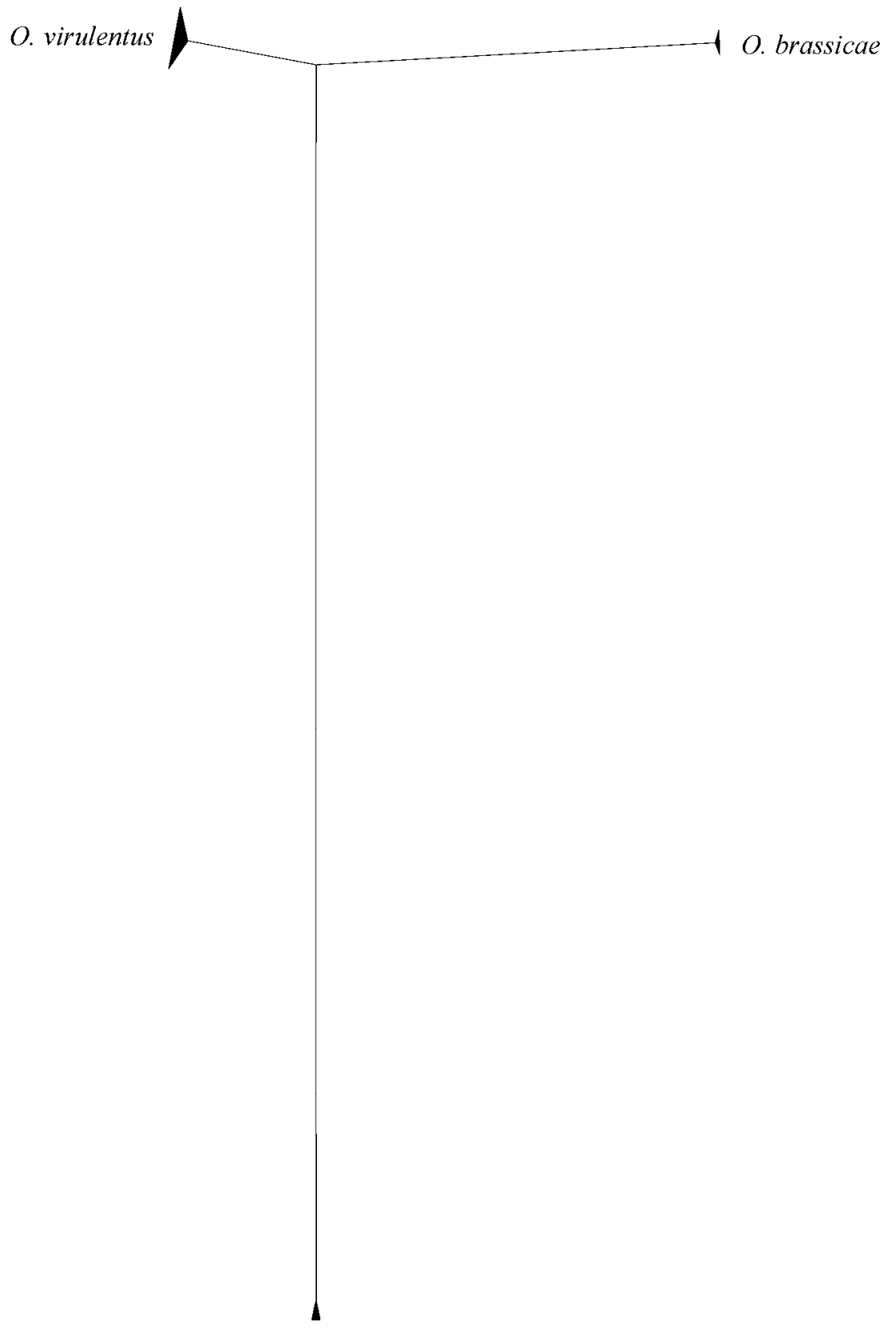

O. bornovanus

0.05

Fig. 3. Phylogenetic tree showing relative genetic distance between the three virus vector Olpidium species: $O$. bornovanus, $O$. brassicae, and $O$. virulentus. The tree was generated in MEGA 4.1 using default parameters. Scale bar represents a genetic distance of 0.05 for branch lengths. 
MLBVV and the TStV strain of LBVaV (23), and that $O$. brassicae does not infect lettuce $(7,13,23)$. However, it contrasts with previous publications (e.g., 4,17,25,27), which named $O$. brassicae as vector of LBVaV and MLBVV.

Sasaya and Koganezawa (23) reported that the extent of nucleotide sequence identity in the complete rDNA-ITS region of $O$. virulentus and $O$. brassicae isolates was 98.5 to $100 \%$ and 99.3 to $100 \%$, respectively, while it was 79.7 to $81.8 \%$ between the two species. This is consistent with the percent identities found in our study within isolates of $O$. virulentus from Australia, Europe, and Japan (97.9 to $100 \%$ ), and of $O$. brassicae from Europe and Japan (99.3 to $100 \%$ ). However, the percent rDNA-ITS region nucleotide sequence divergence between $O$. brassicae and $O$. virulentus isolates that we found was somewhat greater (76.9 to $79.4 \%$ ). This degree of sequence divergence supports the conclusion made by Sahtiyanci (21) based on morphological evidence, and Sasaya and Koganezawa (23) based on molecular evidence, that they are distinct Olpidium species, not simply different strains of the same species. When the nucleotide sequences from the complete rDNA-ITS region of five $O$. virulentus isolates from samples of lettuce roots from Australia and those of the complete rDNAITS region of $10 \mathrm{O}$. virulentus isolates from Europe and Japan were analyzed phylogenetically, two clades were found (I and II), and within clade I, four subclades were distinguishable (Ia-Id). Australian isolates grouped within both clades and within clade I, subclades Ia and Id. Japanese isolates fitted within both clades and in all subclades except Ib, while European isolates only fitted in subclades Ib and Id. When the partial rDNA-ITS region se- quences of two additional southwest Australian isolates, four from Europe, and four from the Americas were included in the analyses, the Australian isolates were within subclades Ia and Id, the European isolates within subclade Ic, and the American isolates within subclades Ia and Ib. One of the Australian farms sampled contained isolate sequences that fitted not only into both of the clades but also into two subclades (Ia and Id), while the second farm contained isolates within the same subclades. This suggests that since European settlement of southwest Australia more than 175 years ago and the subsequent introduction of plant cultivation to the region, three separate introductions of $O$. virulentus have occurred. The data indicate that there have been four separate introductions to Japan. Although Japanese isolates showed the greatest nucleotide sequence diversity for the rDNA-ITS region of $O$. virulentus, this does not mean that this species originated in Japan, as it is not a recognized center of crop domestication. Lettuce was probably domesticated first in Egypt (16). From there, lettuce cultivation spread through the Mediterranean region, first into Italy and then to Greece (29). Assuming that $O$. virulentus evolved with lettuce in its original center of domestication within the Mediterranean Basin, greater nucleotide sequence diversity of $O$. virulentus would be expected in this region than elsewhere. However, unlike Japanese and Australian isolates, European isolates did not fit into both clades, only into three subclades of clade I. Sequencing of more isolates from the Mediterranean region and Europe in general is required to reveal the extent of diversity in the $O$. virulentus population in that part of the world. Further sequencing of the rDNA-ITS region of $O$. virulentus

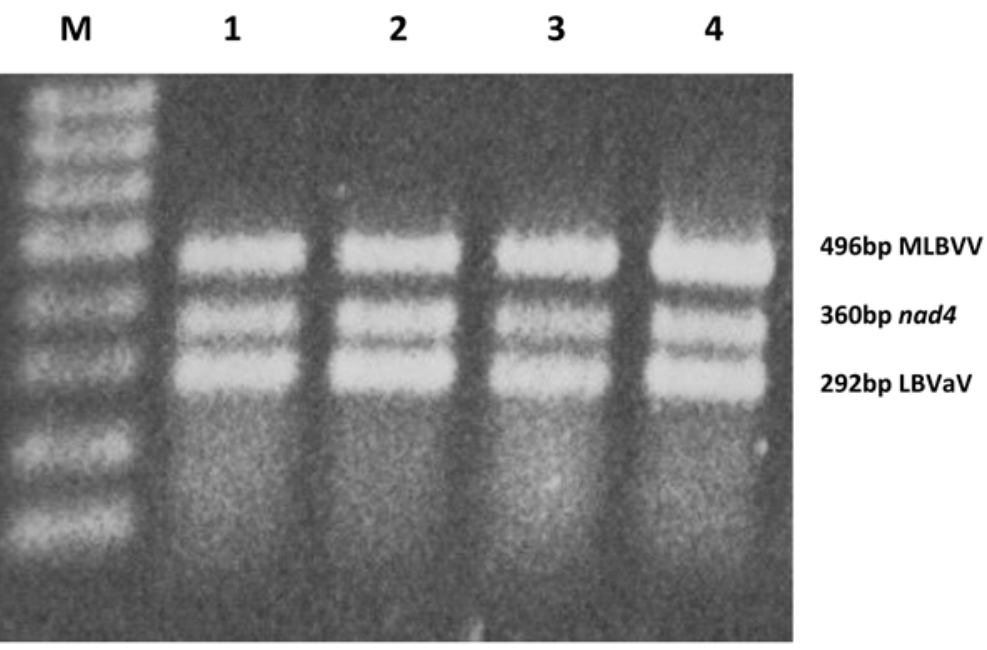

Fig. 4. Agarose gel resulting from a multiplex reverse transcription-polymerase chain reaction to detect the presence of Mirafiori lettuce big-vein virus (MLBVV), Lettuce big-vein associated virus (LBVaV), and control gene nad4 in four samples of lettuce with lettuce big-vein disease from southwest Australia. All samples had mixed infection with LBVaV and MLBVV, and were positive for nad4. Lane 1: isolate Nan 6, lane 2: Nan 7, lane 3: Nan 8, lane 4: Col 1. Lane M represents a 100-bp molecular weight marker. isolates from the Americas is needed to comment on the number of possible introductions there, but more sequence diversity would be expected than that in Australia given the longer history of plant cultivation since European colonization.

Methyl bromide was formerly used widely as a fungicide to control Olpidium spp., but it is no longer available in some countries, including Australia. Environmentally friendly cultural (agronomic) and phytosanitary control measures against Olpidium vectors were included within the LBVD integrated disease management strategies for nurseries, nutrient film, infested land, and uninfested land of Jones (12). For example, when infested land is used, decreasing irrigation and/or placing plastic mulch on the soil surface when overhead irrigation is used diminishes the mobility of viruliferous $O$. virulentus zoospores (14).

\section{ACKNOWLEDGMENTS}

We thank Stephen Wylie and Craig Webster for their advice on nucleotide sequencing, local farmers for allowing sampling on their farms, and Frances Brigg and Julie Uhlmann for operating sequencing machines and the SABC for providing laboratory facilities. Linda Maccarone received an Australian Postgraduate Award (Industry) jointly funded by the Australian Research Council and the Department of Agriculture and Food Western Australia.

\section{LITERATURE CITED}

1. Barr, D. J. S. 1988. Zoosporic plant parasites as fungal vectors of viruses: Taxonomy and life cycle of species involved. Pages 123-137 in: Viruses with Fungal Vectors. J. I. Cooper and M. J. C. Asher, eds. Association of Applied Biologists, Wellesbourne, UK.

2. Campbell, R. N. 1985. Longevity of Olpidium brassicae in air-dried soil and the persistence of the lettuce big-vein agent. Can. J. Bot. 63:2288-2289.

3. Campbell, R. N. 1996. Fungal transmission of plant viruses. Annu. Rev. Phytopathol. 34: 87108.

4. Campbell, R. N., and Grogan, R. G. 1964 Acquisition and transmission of lettuce bigvein virus by Olpidium brassicae. Phytopathology 54:681-690.

5. Campbell, R. N., and Lin, M. T. 1976. Morphology and thermal death point of Olpidium brassicae. Am. J. Bot. 63:826-832

6. Hall, T. A. 1999. BioEdit: A user-friendly biological sequence alignment editor and analysis program for Windows 95/98/NT. Nucleic Acids Sympos. Ser. 41:95-98.

7. Hartwright, L. M., Hunter, P. J., and Walsh, J. A. 2009. A comparison of Olpidium isolates from a range of host plants using internal transcribed spacer sequence analysis and host range studies. Mycol. Res. doi: 10.1016/ j.mycres.2009.09.008

8. Herrera-Vasquez, J. A., Cebrian, M. C., AlfaroFernandez, A., Cordoba-Selles, M. D., and Jorda, C. 2009. Multiplex PCR assay for the simultaneous detection and differentiation of Olpidium bornovanus, Olpidium brassicae and Olpidium virulentus. Mycol. Res. 113:602610.

9. Herrera-Vasquez, J. A., Cordoba-Selles, M. D. Cebrian, M. C., Rosello, J. A., and Jorda, C. 2010. Genetic diversity of Melon necrotic spot virus and Olpidium isolates from different origins. Plant Pathol. In press.

10. Jagger, I. C., and Chandler, N. 1934. Big-vein, 
a disease of lettuce. Phytopathology 24:12531256.

11. James, T. Y., Letcher, P. M., Longcore, J. E., Mozley-Standridge, S. E., Porter, D., Powell, M. J., Griffith, G. W., and Vilgalys, R. 2006. A molecular phylogeny of flagellated fungi (Chytridiomycota) and description of a new phylum (Blastocladiomycota). Mycologia 98:860-871.

12. Jones, R. A. C. 2004. Using epidemiological information to develop effective integrated virus disease management strategies. Virus Res. 100:5-30.

13. Koganezawa, H., Inoue, H., and Sasaya, J. 2005. Host specificity and multiplication of eight isolates of Olpidium brassicae sensu lato and its related Olpidium spp. Bull. Natl. Agric. Res. Cent. West Reg. 4:39-40.

14. Latham, L. J., and Jones, R. A. C. 2004. Deploying partially resistant genotypes and plastic mulch on the soil surface to suppress spread of lettuce big-vein disease in lettuce. Aust. J. Agric. Res. 55:131-138.

15. Latham, L. J., Jones, R. A. C., and McKirdy, S. J. 2004. Lettuce big-vein disease: Sources, patterns of spread, and losses. Aust. J. Agric. Res. 55:125-130.

16. Lindqvist, K. 1960. On the origin of cultivated lettuce. Hereditas 46:319-350.

17. Lot, H., Campbell, R. N., Souche, S., Milne, R. G., and Roggero, P. 2002. Transmission by Olpidium brassicae of Mirafiori lettuce virus and Lettuce big-vein virus, and their roles in lettuce big-vein etiology. Phytopathology
92:288-293.

18. Navarro, J. A., Botella, F., Maruhenda, A., Sastre, P., Sànchez-Pina, M. A., and Pallas, V. 2004. Comparative infection progress analysis of Lettuce big-vein virus and Mirafiori lettuce virus in lettuce crops by developed molecular diagnosis techniques. Phytopathology 94:470477.

19. Rochon, D'A., Kakani, K., Robbins, M., and Reade, R. 2004. Molecular aspects of plant virus transmission by Olpidium and Plasmodiophorid vectors. Annu. Rev. Phytopathol. 42:211-241.

20. Roggero, P., Ciuffo, M., Vaira, A. M., Accotto, G. P., Masenga, V., and Milne, R. G. 2000. An Ophiovirus isolated from lettuce with big-vein symptoms. Arch. Virol. 145:2629-2642.

21. Sahtiyanci, S. 1962. Studien über einige wurzelparasitäre Olpidiaceen. Arch. Microbiol. 41:187-228.

22. Sambrook, J., and Russell, D. W. 2001. Molecular Cloning: A Laboratory Manual. Cold Spring Harbor Laboratory, Cold Spring Harbor, NY.

23. Sasaya, T., and Koganezawa, H. 2006. Molecular analysis and virus transmission tests place Olpidium virulentus, a vector of Mirafiori lettuce big-vein virus and Tobacco stunt virus, as a distinct species rather than a strain of Olpidium brassicae. J. Gen. Plant Pathol. 72:20-25.

24. Tamura, K., Dudley, J., Nei, M., and Kumar, S. 2007. MEGA4: Molecular Evolutionary Ge- netics Analysis (MEGA) software version 4.0. Mol. Biol. Evol. 24:1596-1599.

25. Teakle, D. S. 1988. The effect of environmental factors on fungus-transmitted viruses and their vectors. Pages 167-179 in: Viruses with Fungal Vectors. J. I. Cooper and M. J. C. Asher, eds. Association of Applied Biologists, Wellesbourne, UK.

26. Thompson, J. D., Higgins, D. G., and Gibson, T. J. 1994. CLUSTAL W: Improving the sensitivity of progressive multiple sequence alignment through sequence weighting, positionspecific gap penalties and weight matrix choice. Nucleic Acids Res. 22:4673-4680.

27. Walsh, J. A. 1994. Effects of some biotic and abiotic factors on symptom expression of lettuce big-vein virus in lettuce (Lactuca sativa). J. Hortic. Sci. 69:21-28.

28. Westerlund, F. V., Campbell, R. N., and Grogan, R. G. 1978. Effect of temperature on transmission, translocation, and persistence of the lettuce big-vein agent and big-vein symptom expression. Phytopathology 68:921-926.

29. Whitaker, T. W. 1969. Salads for everyone - A look at the lettuce plant. Econ. Bot. 23:261264.

30. White, T. J., Bruns, T., Lee, S., and Taylor, J. W. 1990. Amplification and direct sequencing of fungal ribosomal RNA genes for polygenetics. Pages 315-322 in: PCR Protocols: A Guide to Methods and Applications. M. A. Inns, D. H. Gelfand, J. J. Sninsky, and T. J. White, eds. Academic Press, New York. 